\title{
Henry van de Velde, 0 art nouveau e a utopia da reconciliação
}

\author{
Henri van de Velde, the art nouveau \\ and the utopia of the reconciliation
}

por Alice de Oliveira Viana

\begin{abstract}
RESUMO
0 presente artigo apresenta parte do pensamento e da obra do arquiteto e designer belga Henri van de Velde, entendido como um dos precursores da linguagem art nouveau, cujas produções práticas recorrentemente apresentaram certa referência formal à natureza, assim como seu pensamento teórico se fundamentou em uma explícita associação aos processos naturais. Em seguida, a partir da análise de algumas imagens de suas produções e entendendo que a imagem pode operar oscilando em termos de visível-invisível, procura-se demonstrar que esta aparente confiança na natureza e em seus processos em grande medida traveste-se, de modo velado, de uma problemática da época, a inelutável separação entre arte e técnica, a tentativa irresoluta de unir novamente homem e natureza. Pretende-se, com este estudo, trazer contribuições para a área da Teoria e História das Artes Visuais.
\end{abstract}

Palavras-chave Henri van de Velde; Art Nouveau; Técnica; Natureza

\section{ABSTRACT}

The present article presents part of the thought and work of Belgian designer and architect Henri van de Velde, understood as a precursor of art nouveau language, whose pratical productions repeatedly had some formal reference to the nature, as well as his theoretical thinking had based on an explicit association with natural processes. Then, from analysis of some images of his productions and understanding that the image can operate ranging from visible-invisible, seeks to show that this apparent belief in nature and its processes largely masks, in a veiled way, of a question of time, the inevitable separation between art and technique, the insolvable attempt to reunite again man and nature. It is intended, with this study, to bring contributions to the field of Theory and History of Visual Arts.

Keywords Henri van de Velde; Art Nouveau; Technique; Nature 


\section{Henry van de Velde e a natureza do ornamento}

Os calorosos debates que tiveram voz no século XIX em torno da problemática da validade estética do ornamento, na acepção de Josep Ryckwert (1979), foram responsáveis em grande medida por distorcer a anterior concepção deste elemento deveras importante da arquitetura e das artes em geral, passando a considerá-lo algo meramente supérfluo, adicionado à construção, justamente por isto, desnecessário. 0 ornamento, que anteriormente deveria transmitir uma mensagem ao observador, "vestir" um personagem diante dos habitantes da cidade, teria sido relegado em detrimento da forma pura, da forma que mostrava o objeto "tal como ele deveria ser" (RYKWERT, 1979, p.05).

Estas idéias, aparentemente tão inocentes, e reforçadas fortemente no texto original através de letras maiúsculas, teriam sido proclamadas e difundidas por Henry van de Velde, um dos precursores da linguagem art nouveau e um dos principais responsáveis pela criação daquilo que o próprio designaria de "novo estilo", o estilo onde os objetos poderiam se oferecer a seus usuários a partir de suas formas "essenciais".

Foi mais especificamente a partir da última década do século XIX que o belga Henry Clemens van de Velde (1863-1957) teria mergulhado na cruzada em prol de uma reformulação das artes de seu tempo. Após um curto período dedicado à pintura, van de Velde se volta para a arquitetura e para o design' áreas as quais, por seu viés de necessidade e utilidade - de acordo com o mesmo (1959) -, facilitariam esta reformulação. Esta mudança se fazia estritamente necessária uma vez que "as formas reais das coisas estavam encobertas. Naquele momento, a revolta contra a falsificação das formas e contra o passado constituía uma revolta moral", conforme teria van de Velde declarado para Sigfried Giedion anos mais tarde (GIEDION, 2004, p.323).

Foi esta revolta contra a atitude de seu tempo frente à arte e também frente aos estilos artísticos do passado que o fez se engajar nos debates em torno do ornamento. Tendo entrado em contato com as ideias de John Ruskin² e William Morris ${ }^{3}$, defensores do gótico, van de Velde assim como estes proclamava acreditar que a

1 É importante destacar que é neste século XIX que o design está se formando enquanto um campo de conhecimento em virtude das mudanças na técnica de produção dos objetos devido à Revolução Industrial. Mostra-se imprescindível neste momento planejar, estudar e adequar os objetos às necessidades da época.

2 John Ruskin (1819-1900), pensador britânico que teorizou, dentre inúmeros assuntos, especialmente sobre arte e arquitetura. Foi um dos defensores do gótico e um dos responsáveis pela criação do Movimento Arts $\circlearrowright$ Crafts, que defendia o artesanato como alternativa à produção industrial em massa.

3 Seguidor do pensamento de Ruskin estava o artista e teórico britânico William Morris (18341896), mais diretamente comprometido com o Movimento Arts $\circlearrowright$ Crafts. 
decadência da arte teria se iniciado naquele período a que os homens, com bastante mau gosto - na acepção de van de Velde -, designaram de "Renascimento" (VAN DE VELDE, 1959). Um momento de infertilidade moral e espiritual, onde ingenuamente a pintura e a escultura teriam renunciado a sua mais alta missão, a de formar parte de um todo ornamental, em detrimento de uma existência solitária, acima do cavalete ou do pedestal isolado. A pintura e a escultura penetraram então nas residências privadas e teriam a partir deste momento se tornado anedóticas, não mais se submetendo a uma idéia elevada, espiritual, mas servindo agora como um capricho arbitrário (VAN DE VELDE, 1959). Entretanto, uma nova esperança estaria despontando com o desenvolvimento das artes decorativas do século XIX. Estas deveriam reabilitar a anterior função ornamental da pintura, da escultura e da arquitetura, bem como a síntese das mesmas em prol da unidade das artes como a que existira no período de esplendorgótico (VAN DE VELDE, 1959).

Em decorrência desta concepção ornamental e sintética das artes, van de Velde elaboraria sua definição de ornamento moderno, cujas premissas já indicariam o embrião do design funcional da modernidade do século XX. 0 ornamento moderno, de acordo com van de Velde, teria como aspecto primordial a utilidade, ou seja, suas formas deveriam atender a este requisito. Daí a necessidade de formas essenciais, puras, que demonstrassem certa franqueza no processo de elaboração. Deste modo, a beleza surgiria do próprio objeto, não de algo que lhe fosse exterior, como da arbitrariedade fantasiosa dos artistas da época:

Esta ornamentación es ante todo necesaria, surge del objeto mismo, al que queda siempre unida, indica su finalidad o su proceso de formación y le ayuda a adaptarse todavía más a la tarea que le corresponde, a su utilidad (VAN DE VELDE, 1959, p.69).

Deste aspecto da utilidade decorreria, em grande medida, uma das principais características do ornamento propugnadas por van de Velde, a necessidade de ser abstrato, distante de qualquer referência ao passado e de qualquer instância exterior à própria forma:

La ornamentación no está sometida a otras leyes que no sean las que le impone su finalidad, en su búsqueda de armonía y equilibrio. Jamás pretende representar algo. Debe tener libertad para no representar nada, pues sin ella no podría sostenerse (VAN DE VELDE, 1959, p.69).

Outro aspecto fundamental do pensamento teórico de van de Velde seria a relação com a natureza, um tema característico da linguagem art nouveau. Em grande parte de suas obras construídas percebemos constantemente certa alusão à natureza e podemos estender esta afirmativa também para seu trabalho escrito, uma vez que o designer está recorrentemente fazendo analogias com a mesma para descrever suas idéias:

Un mueble, en particular, se revela como unidad cuando todas las piezas complementarias, tales como tornillos, bisagras, cerrojos, (...) no permanecen como piezas 
autónomas, sino que se fusionan con él...; de otro modo no se logra aquella unidad a la que aspiramos por sobre todas las demás cualidades (...)

Tales piezas complementarias son indispensables, y completan los órganos naturales del objeto; pero se asemejan a brotes que, de acuerdo con la destreza con que se injertan, toman parte en la vida del todo o se extinguen. (VAN DE VELDE, 1959, p.50).

Teria sido esta lógica da natureza e de seus processos - algo estudado pelas ciências naturais naquele momento - aquilo a que van de Velde recorria para elaborar sua defesa dos valores morais, de verdade e funcionalidade, conforme ele mesmo declara nesta afirmação:

Ya ustedes habrán adivinado que contrapongo la palabra moral a lo falso, a lo estúpido, a lo no verdadero. Tiendo a ver como moral todo cuanto esté en armonía con la naturaleza de las cosas y con los procesos naturales. Sostengo que, en la naturaleza, todo aspira al punto máximo de la fuerza, del bienestar y de la dicha, y todo lo que se aparta de esto lo llamo inmoral (p.82)

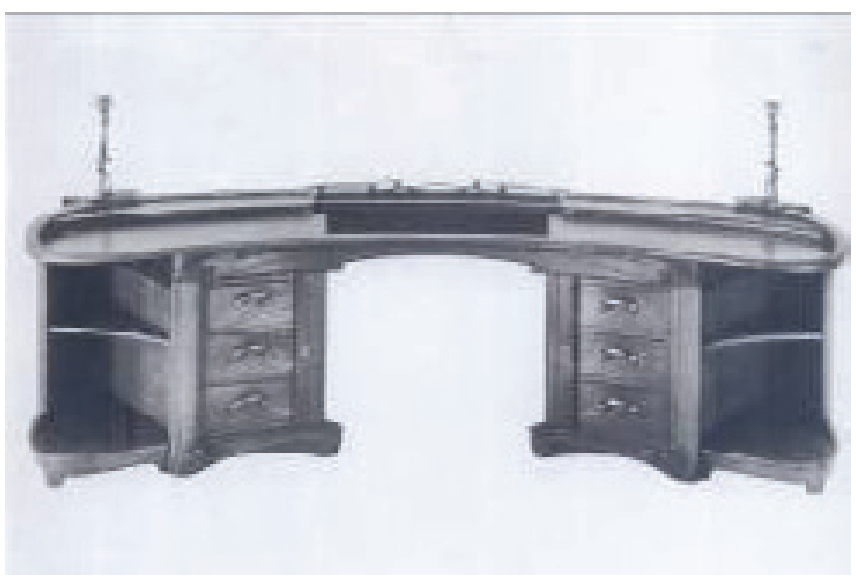

Figura 01 - Henry van de Velde, escrivaninha. Fonte: SEMBACH, Klaus-Jurgen. Arte Nova. Koln: Taschen, 2007

Durante o século XIX, conforme declara Pevsner, "as ciências naturais eram idolatradas" (1996, p.73). Não somente o art nouveau, mas também a obra de outros teóricos, artistas e arquitetos apresentava referências à natureza ${ }^{4}$, alguns refletindo uma particular aproximação entre a arte e a arquitetura às ciências naturais na época.

4 John Ruskin, em sua obra de 1849, The Seven Lamps of Architecture (New York: Dover Publications, 1989), defendia que as formas belas seriam aquelas que possuíssem alguma semelhança formal com a natureza, que era fruto da criação divina. Assim também o era para o artista e teórico William Morris, para quem a natureza adquirira uma condição sagrada (ARGAN, 1992). Louis Sullivan (1856-1924), arquiteto norte-americano, aproximou-se das idéias evolucionistas do século XIX e defendia que o ornamento deveria estar vinculado à construção e deveria "brotar do material de que é feito, assim como as flores brotam das folhas de uma planta" (SULLIVAN apud PAIM, 2000, p.55). 
Para William Morris, tudo na natureza seria útil e único, e assim também deveria ser a obra de arte, servir para alguma coisa e, o que era essencial, ser produzida como objeto único, pelas mãos de um artista-artesão (PEVSNER, 1996), pensamento este que deixou seguidores, como o próprio van de Velde 5 .

De certo modo era contra a separação das antigas relações homem-natureza que estes pensadores se posicionavam. Pode-se afirmar que foi em grande medida a partir do lluminismo e das modificações operadas por este sobre a tradição que estas relações se alteram mais profundamente. Ciulio Carlo Argan (1992) aponta a transformação do processo tecnológico do artesanato - que reproduzia os processos da natureza, para a tecnologia industrial - que opera sobre a natureza e modifica o ambiente, como uma das crises da arte após o século XVIII.

Entretanto, em grande medida, parte da obra de van de Velde e de alguns de seus contemporâneos, contrariamente ao que se deduz, não refletirá está confiança na natureza e na analogia com seus processos que se costuma atribuir aos objetos art nouveau, tampouco se apresentará como completamente abstrata, conforme o designer defendia.

\section{0 disfarce}

Ao olharmos para algumas produções de van de Velde, algo nos leva a querer afirmar que não há abstração dominante como o mesmo defendia, que as formas não se apresentam assim tão autônomas (figuras 02 e 03).

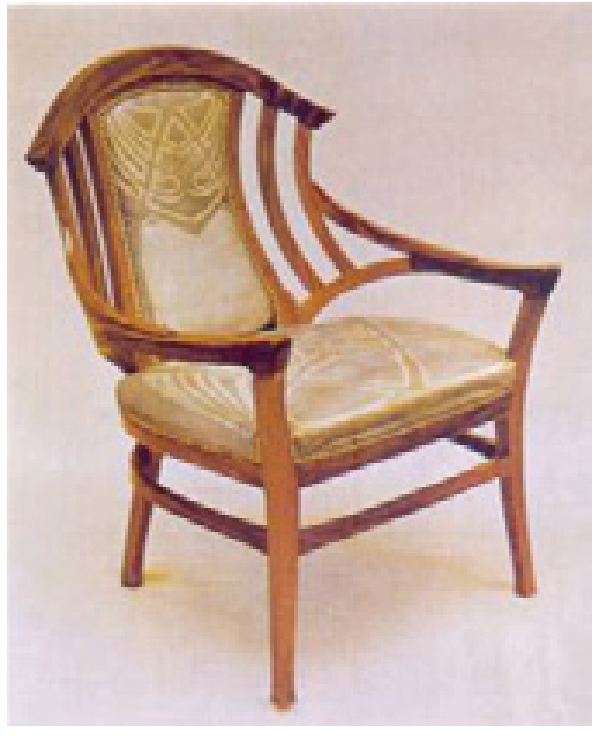

Figura 02 - Henry van de Velde, cadeira de braços, 1898. Fonte: SEMBACH, Klaus-Jurgen. Arte Nova. Koln: Taschen, 2007

5 William Morris, conforme já se afirmou, foi um dos responsáveis pela constituição do Movimento Arts $\Theta$ Crafts. Este movimento defendia o fim da distinção entre artesão e artista, e a criação artesanal de objetos únicos, individuais, não reproduzíveis, em contraponto à produção mecanizada industrial, responsável pela repetição e padronização dos objetos naquele momento. 


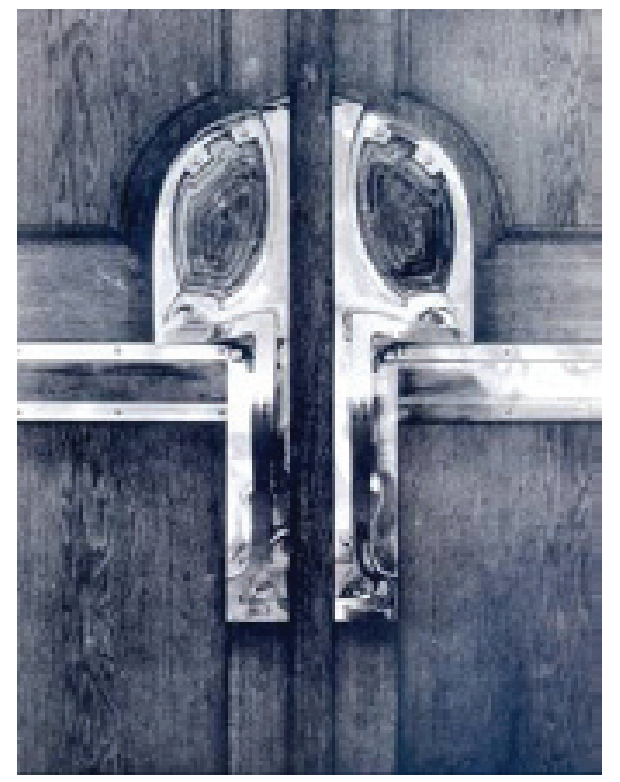

Figura 03 - Henry van de Velde, puxadores de porta do Arquivo Nietzsche em Weimar, 1903. Fonte: SEMBACH, Klaus-Jurgen. Arte Nova. Koln: Taschen, 2007

A cadeira acima (figura 02) foi criada no ano de 1898, momento quando van de Velde estava iniciando sua carreira. No estampado do tecido algo se assemelha à imagem de uma figura monstruosa, lembrando uma máscara. Uma maior "obtusidade" - se assim se pode dizer de uma imagem que nos oferece algumas vezes como disfarce esquivo, como cintilação intermitente - é suscitada pela imagem deste puxador de porta (figura 03) que van de Velde elaborou para o Arquivo Nietzsche na cidade de Weimar 6 .

De fato, algo nesta imagem se nos apresenta como além de um simples puxador de porta elaborado no mais fiel "estilo floral", de linhas sinuosas advindas de uma natureza estilizada. Algo semelhante a uma face aterradora cintila nesta imagem. Dois olhos profundos, um nariz e uma possível boca angustiada a nos olhar.

Pode-se perceber esta imagem (figura 03) como um close, um rosto, rosto que muitas vezes pode-se apresentar como disfarce, travestimento. 0 close do cinema é um rosto; Walter Benjamin anunciava o surgimento do inconsciente óptico da imagem através do close (BENJAMIN, 1994), aquilo que indicaria os lapsos, as faIhas e o que está de certo modo reprimido. 0 que ela indica? 0 que ressoa nestes dois profundos olhos?

Pensando que a imagem fala em termos do visível-invisível, do que está presente e ausente, e que, segundo Merleau-Ponty, este corpo que vê a imagem seria "ao mesmo tempo vidente e visível", podendo "também se olhar, e reconhecer no que

6 Seguindo o pensamento de Roland Barthes (1984), pode-se dizer que, ao olharmos para estas imagens, um sentido obtuso invade nossa percepção, um sentido "ao mesmo tempo teimoso e fugidio, liso e esquivo" (1984, p.45), que se percebe na minúcia, em detalhes significantes e que, conforme declara Barthes, está além da explicação simplista da psicologia, da anedota, da mera função. 
vê então o 'outro lado' de seu poder vidente" (2004, p.17), podemos sugerir que não seria o olho que olha, mas sim o olhar?.

0 documentário "Janela da Alma" (JARDIM; CARVALHO, 2002) procurou demonstrar como o ato de ver é mediado pelo olhar, que dá acesso a outras realidades, realidades da ordem do invisível. A imagem, neste sentido, é um exercício do olhar, que demanda uma atitude de crença, atitude de enxergar não o visual, mas sim aquilo que se torna visível, levando-nos a crer que não somos nós que olhamos, mas sim a imagem que nos olha (DIDI-HUBERMANN, 1998).

Outras obras do mesmo designer, como as arquiteturas mostradas nas figuras 04 e 05, irão apresentar, em maior ou menor grau esta face aterradora, esta máscara a nos olhar, que, em grande medida, nestas fachadas não comunicam em nada a leveza habitual dos objetos e arquiteturas que estavam sendo produzidos à época, ao menos relativo a sua elevação principal, sua vista frontal, suposta apresentação da obra à cidade ao redor.

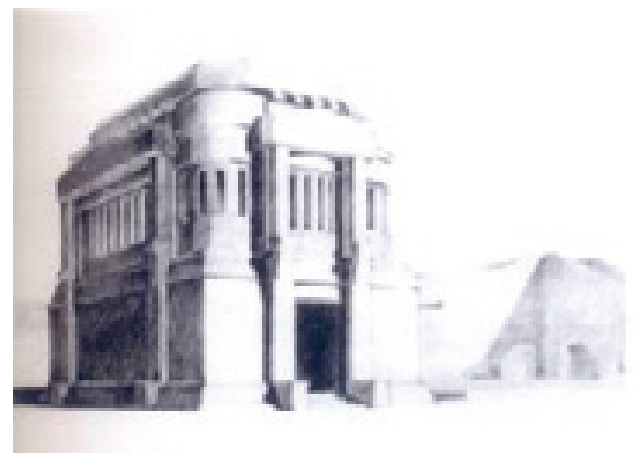

Figura 04 - Henry van de Velde, projeto para o estádio Nietzsche em Weimar, 1911/12. Fonte: SEMBACH, Klaus-Jurgen. Arte Nova. Koln: Taschen, 2007.

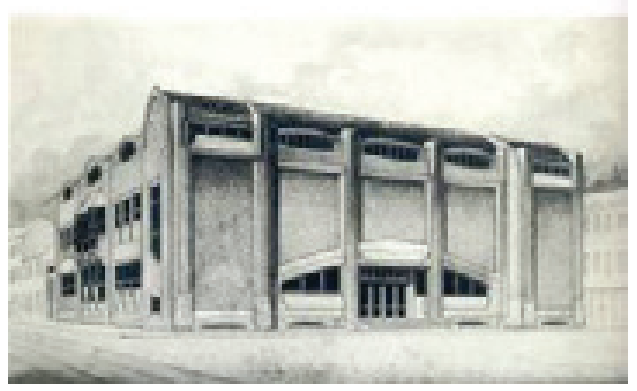

Figura 05 - Henry van de Velde, projeto para um museu de Artes Aplicadas em Weimar, 1903/04. Fonte: SEMBACH, Klaus-Jurgen. Arte Nova. Koln: Taschen, 2007.

É notável perceber, também, que estas duas imagens acima, dois supostos projetos arquitetônicos, não possuem relação alguma com a cidade ao seu redor, o estádio apresenta-se isolado, em meio a um quase vazio, e o segundo, apesar de inserido na malha urbana e alinhado a esta, em sua fachada contígua ao casario parece não estabelecer qualquer tentativa de comunicação formal com o entorno, algo que contraria as práticas comuns de decoro urbano da época.

Afirmar, como muitos o têm feito, que a produção de van de Velde é pautada em parte por um design floral, explorando linhas sinuosas e formas que aludem à natureza, em uma analogia confiante na natureza - e isto de certa forma poderia

7 Constatações semelhantes as que Merleau-Ponty pôde fazer acerca da pintura de Cézanne e que podem ser percebidas neste comentário onde o mesmo cita Cézanne, no texto A dúvida de Cézanne: "A paisagem, ele dizia, pensa-se em mim e eu sou sua consciência" (MERLEAU-PONTY, 2004, p.133). 
se estender também para o art nouveau de um modo geral - seria ser superficial, seria ler a obra através da clave do contexto e do mero funcionalismo, não notando a consistência fantasmática da imagem, o rasgo entre o que vemos e aquilo que nos olha, aquilo que é e ao mesmo tempo não é, onde se anulam fundamentos como autonomia ou historicidade da obra.

\section{A projeção empática - a defesa da vida}

Se por um lado o designer afirmava que seu princípio do ornamento deveria ser abstrato, não representar coisa alguma, por outro, o ornamento moderno de van de Velde deveria indicar, de acordo com o mesmo, através do que ele designava linhas-força, a energia depositada sobre o objeto, princípio que van de Velde teria elaborado através da noção de Einfühlung com a qual o mesmo, de acordo com Frampton (2003), teria entrado em contato e a partir da qual ele elaboraria esta sua idéia das linhas-força:

Una línea es una fuerza que, al igual que todas las fuerzas elementales, está en actividad; varias líneas puestas en relación, pero contrapuestas, provocan el mismo efecto que varias fuerzas elementales que actuán en oposición. Esta verdad es decisiva, como base de la nueva ornamentación (...) Cuando digo que una línea es una fuerza, sólo sostengo algo absolutamente real. Ella recibe su fuerza de la energía de quien la trazó. Esa fuerza y esa energía actúan sobre el mecanismo del ojo de manera que lo obligan a seguir direcciones. Estas direcciones se complementan, se funden entre sí y componen finalmente determinadas formas (VAN DE VELDE, 1959, p.92-93)

Foi a partir do século XIX que se desenvolveram, a partir dos estudos de filósofos alemães, a noção de Einfühlung, ou, na acepção de Frampton, "empatia", "projeção quase mística do ego criador no objeto" (FRAMPTON, 2003, p.113). Esta noção leva em consideração a projeção dos sentimentos na forma do objeto, ou seja, considerava que as formas e direções das linhas indicavam estados de espírito, como exaltação para formas ascendentes, tristeza para as linhas baixas e descendentes, entre outros. A linha deveria carregar e projetar a energia do homem no trabalho a ser feito, daí a denominação de linhas-força.

Deste modo, Henry van de Velde estava interessado, como ele próprio afirmou, nestes "matices afectivos que uno puede provocar, con ayuda de los ornamentos, cuya esência descansa en intencionadas y expresivas manifestaciones de alegria, fatiga, serenidad, abrigo, movimiento y reposo" (VAN DE VELDE, 1959, p.66).

É importante recordar que van de Velde, no momento onde desenvolve seus princípios teóricos, está vivendo na Alemanha. E foi na Alemanha desta época - finais do século XIX e princípios do XX - que parte da estética expressionista começa a 
se desenvolver, uma estética que receberá grandes contribuições dos estudos da Einfühlung que se desenvolvem então neste país.

Willheim Worringer, teórico alemão, em princípios do século XX publicará sua tese de doutoramento intitulada Abstraktion und Einfühlung ("Abstração e Empatia") que terá grandes repercussões na esfera artística. Nesta obra, Worringer afirma que, devido a uma natureza "áspera e pouco generosa" (1953, p.111) os povos do norte desenvolveram uma relação de distância e de não confiança no meio natural, logo, um sentimento de hesitação e angústia perante as coisas do mundo e sua aparência. Visto este estado de ânimo predominante, a "vontade artística" (Kunstwollen) destas sociedades tenderia para a abstração, para formas geométrico-lineais, não orgânicas, mas formas com uma extrema necessidade de expressão, formas que recorrem a este "inquietante pathos inerente à vivificação do orgâniCO" (WORRINGER, 1953, p.113).

Estas idéias de Worringer teriam adquirido grande importância no desenvolvimento do Expressionismo alemão o qual, em grande medida, manifestou-se como certa tendência à expressão angustiada do homem em relação à existência, um entendimento dramático do existir humano.

Argan define a estética expressionista por oposição ao Impressionismo; este pressupõe um movimento do exterior para o interior, "é a realidade (objeto) que se imprime na consciência (sujeito)" a outra, do interior para o exterior, ou seja, "é o sujeito que por si imprime o objeto" (1992, p.227).

0 Expressionismo teria tido dois eixos principais: França, o denominado grupo dos fauves (feras) e Alemanha com o grupo Die Brücke (a ponte). E estes dois grupos do mesmo modo vão refletir uma diferença essencial no seu posicionamento ante a questão da existência, exemplificada pelo forte contato que os dois tiveram com os pensadores Bergson e Nietzsche, respectivamente. De acordo com Argan:

Para Bergson, a consciência é, no sentido mais amplo do termo, a vida; não uma imóvel representação do real, mas uma comunicação ativa e contínua entre objeto e sujeito. Um único elã vital, intrinsecamente criativo, determina o devir tanto dos fenômenos quanto do pensamento. Para Nietzsche, a consciência é decerto a existência, mas esta é entendida como vontade de existir em luta contra a rigidez dos esquemas lógicos, a inércia do passado que oprime o presente, a negatividade total da história (1992, p.228).

0 fato é que ambos os grupos, em grande medida, elaboravam seu trabalho em torno do tema mais geral da vida, da existência humana, tendo o grupo alemão se posicionado tendendo mais a certo tipo de angústia diante da existência, da realidade, conforme já assinalado.

Deste modo, enquanto o Impressionismo realizava investigações acerca da instância objetiva da imagem e de sua estrutura visual - a partir das impressões captadas do mundo exterior -, o Expressionismo buscaria projetar o "mundo interior" na 
imagem criada, distorcendo as figuras, suas proporções e subvertendo suas cores habituais. Assim sendo, as figuras humanas, por exemplo, não mais obedeceriam às regras de proporção do corpo tradicionalmente empregadas, estariam, desde então, sujeitas a forças externas, resultantes do ego criador do artista (figura 06).

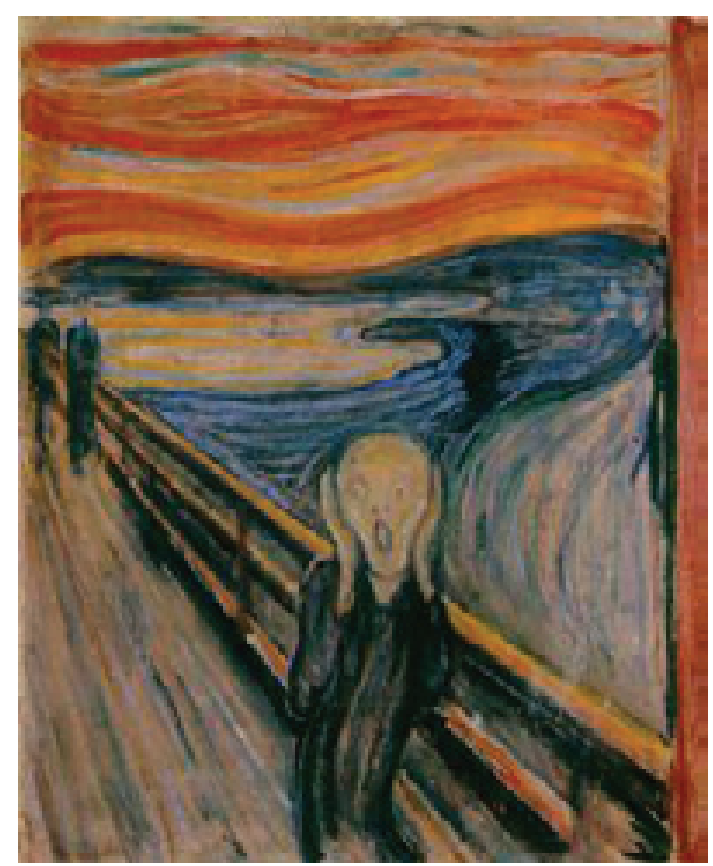

Figura 06 - Edvard Munch, 0 Grito, 1893. Fonte: http://www.infoescola.com/. Acesso em 20. Fev. 2011.

Um movimento semelhante podemos notar no art nouveau - apesar de que este não se pautava pela distorção proposital dos objetos -, uma vez que grande parte de seus objetos passam também a obedecer a esta lógica extrínseca de criação, algo que Rosalind Krauss (1998) observou da mesma forma acerca das esculturas de Rodin.

As obras deste artista, em fins do século XIX, apresentariam, de acordo com Krauss (1998), certa opacidade, uma vez que seu significado se resolveria na superfície, diferentemente da escultura tradicional e acadêmica da época. Na escultura neoclássica, por exemplo, a obra possuía uma mensagem prévia - neste caso, uma mensagem que era em grande medida ideológica - que era formada a partir da estrutura intrínseca do objeto representado, uma prática advinda da tradição clássica da escultura antiga. Seria a estrutura anatômica do corpo humano aquilo que traduziria seu conteúdo, este percebido pela aparência exterior da escultura, através dos gestos e expressões. Ou seja, este tipo de escultura apresentaria certa transparência, clareza de identificação. Rodin vai contra esta tradição, resolve suas esculturas na superfície, borra o contorno - aquilo que definiria a forma do corpo humano -, ou funde o contorno de diferentes figuras, impossibilitando a identificação de onde vem o gesto da escultura, sua expressão. Rodin não comunica diretamente superfície e profundidade anatômica, não faz uma depender ou derivar da outra. Deste modo, ele recusa a relação tradicional direta entre a causa e o efeito, entre a forma e o conteúdo. 
0 mesmo efeito de ênfase na superfície do objeto se sucederia com o art nouve$a u$, na medida em que a aparência de seus objetos não mais seria resultante da estrutura interna do móvel, da relação entre elementos verticais de sustentação e elementos horizontais de travamento, mas sim a partir de efeitos exteriores a eles, como bem observa Krauss:

Sua execução se dá de um modo tal que sentimos estar observando algo moldado pela erosão da rocha pela água, pelos sulcos deixados pelas ondas na areia, ou pelos estragos causados pelo vento; em suma, por aquilo que associamos à passagem de forças naturais sobre a superfície da matéria (1998, p.42).

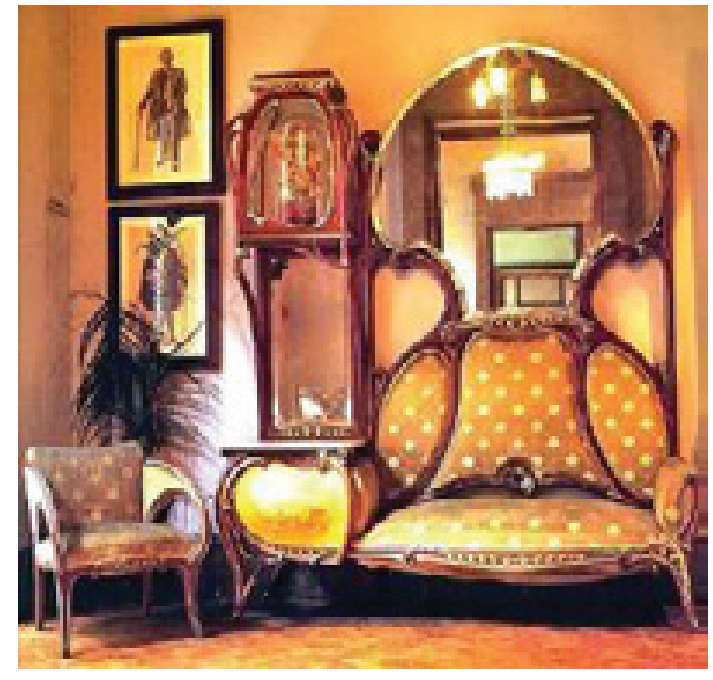

Figura 07 - Mobiliário art nouveau. Fonte: http://www.artemirna.blogspot.com. Acesso em 15 ago.2011.

Este efeito de ênfase na superfície também estaria bastante explícito, posteriormente, nas arquiteturas cunhadas de expressionistas, como, por exemplo, a Torre Einstein de Eric Mendelsohn, que é formada, por exemplo, por forças que parecem ter escavado seus limites externos.

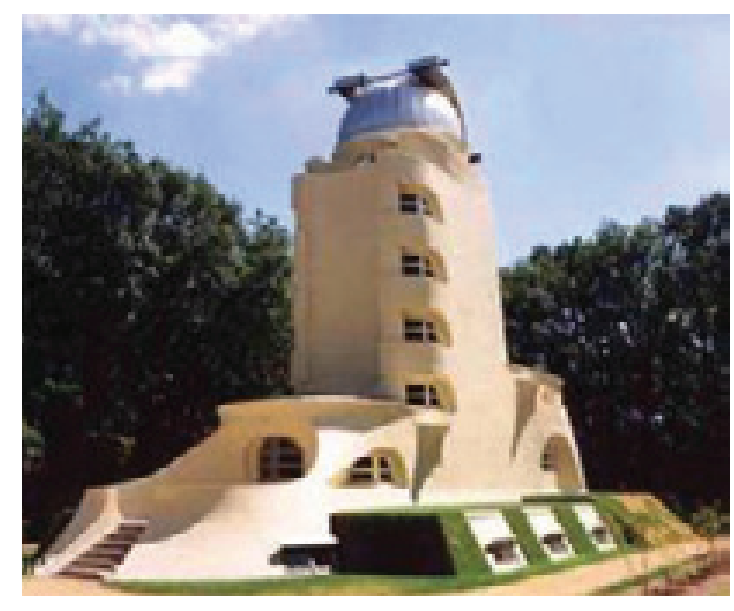

Figura 08 - Eric Mendhelson. Torre Einstein, 1920. Disponível em http://www.dw-world. de/. Acesso em 20. Fev. 2011. 


\section{A harmonia perdida e a utopia da reconciliação}

De um modo geral, esta atitude de criação da forma a partir de forças exteriores indicaria uma mudança crucial na tradição formal tanto das artes quanto da arquitetura. Um momento de afastamento da antiga relação simbólica entre as formas criadas e o corpo humano, em vigor praticamente desde a Antiguidade. No caso da arquitetura, na Antiguidade a beleza foi entendida a partir da noção de harmonia, esta consistia na idéia de proporção das partes com o todo e das partes entre si, onde o módulo mínimo seria o diâmetro da base das colunas. Acreditava-se que a mesma harmonia presidia o corpo humano ideal, onde a altura do homem corresponderia a um múltiplo do tamanho da cabeça. Ou seja, existiria certa correspondência entre os edifícios e o corpo humano. No Renascimento, estabeleceu-se que esta razão harmônica entre as partes e delas com o todo estaria fundamentada em um número fixo estabelecido já na Antiguidade que corresponderia mais ou menos a $\Phi=1,618 \ldots$, tendo ficado este número conhecido como número de ouro ou seção áurea. Acreditava-se que esta razão persistia em todos os corpos belos, assim como na natureza.

Foi a linguagem art nouveau que, em grande medida, rechaçou de vez o cânone da proporção clássica, introduzindo formas até então não usadas que somente aludiam a e estilizavam formas da natureza. E isto também foi em grande medida propiciado pelo advento da técnica. Os novos materiais, como o ferro e o vidro permitiam uma ampla aplicação de formas diferenciadas, cobrindo grandes vãos, aumentando o tamanho das aberturas, reduzindo a proporção das colunas. Enfim, o fato é que neste momento tem-se um definitivo afastamento da antiga relação mimética da arquitetura e dos objetos criados com a natureza.

Ainda sobre o art nouveau, a revista Minotaure em 1933 apresentou um artigo de Salvador Dali onde o autor celebra o que ele chama de "beleza horrível e comestível" do art nouveau, especialmente daquela encontrada na arquitetura de Antonio Caudí em Barcelona (figura 09) ${ }^{8}$. Neste artigo, Dali (2003) reafirma o que se declarou mais acima, o modo pelo qual a estética art nouveau abdicou das formas tradicionais baseadas na seção áurea a favor da "ondulação convulsiva", e ainda traça um paralelo desta beleza horrível encontrada em Gaudí com as fotografias da entrada do metrô de Paris ${ }^{9}$, também em linguagem art nouveau, tiradas por Brassai (figura 10).

80 artigo é intitulado De la beauté terrifiante et comestible, de l'architecture modern style, Minotaure, $n^{\circ} 3 / 4,1933$, foi publicado em espanhol sob o título De la beleza aterradora y comestible del la arquitetura modern style, in: DALI, Salvador. Por qué se ataca a la Gioconda?. Madrid: Siruela, 2003.

9 A entrada do metrô de Paris foi elaborada em linguagem art nouveau, e construída durante os anos de 1899 e 1904 por Hector Guimard, que visivelmente explorou todas as potencialidades dos novos materiais, o ferro e o vidro. 
Briony Fer (FER et al, 1998) aponta que ainda havia outra relação destas imagens acima citadas com a colagem de Dali intitulada 0 fenômeno do êxtase (figura 11), onde ele apresentava várias imagens de mulheres submetidas ao fenômeno da histeria. Ainda de acordo com Fer, os surrealistas entendiam a histeria mais como uma situação passional do que algo patológico, como o queriam certos estudos da época. Fer afirma que para Breton e Aragon, "a histeria é um estado mental mais ou menos irredutível e que é caracterizado pela subversão das relações entre o sujeito e o mundo da moralidade, ao qual ele se opõe, fora de qualquer sistema de delírio" (1998, p. 212). Neste sentido, esta "beleza convulsiva" percebida em certas imagens art nouveau possuiria certa semelhança com a condição da paciente histérica que, para os surrealistas, indicava mais um estado de ruptura com leis repressivas, neste caso, as leis do ângulo reto e da seção áurea.
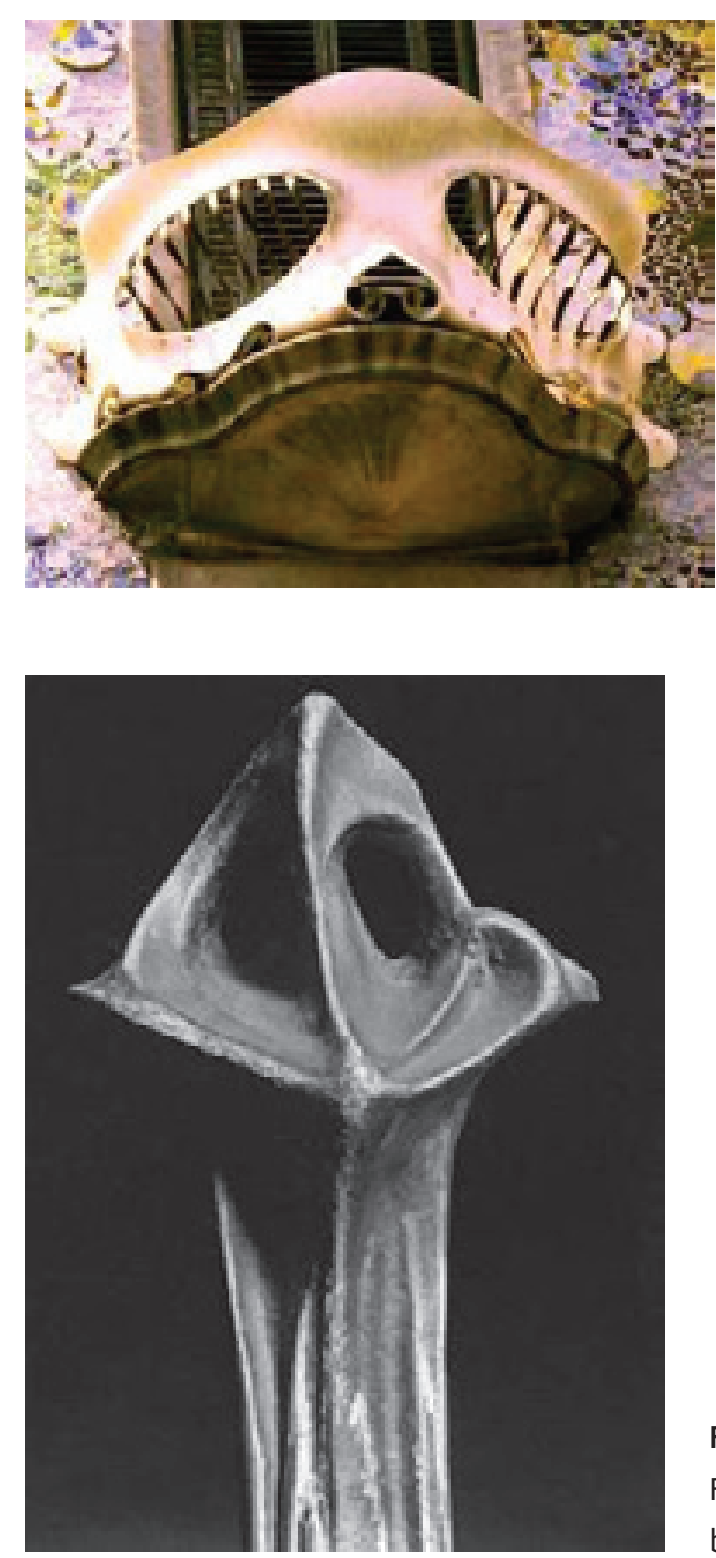

Figura 09 - Antonio Gaudi, balcão da casa Batló, Barcelona. Fonte: 〈http://www.flickr.com/> Acesso em 20. fev. 2010.
Figura 10 - Brassai, fotografia do metrô de Paris. Fonte: 〈http:www.umpostalparaumamigo. blogspot.com/>. Acesso em 20.fev.2010. 


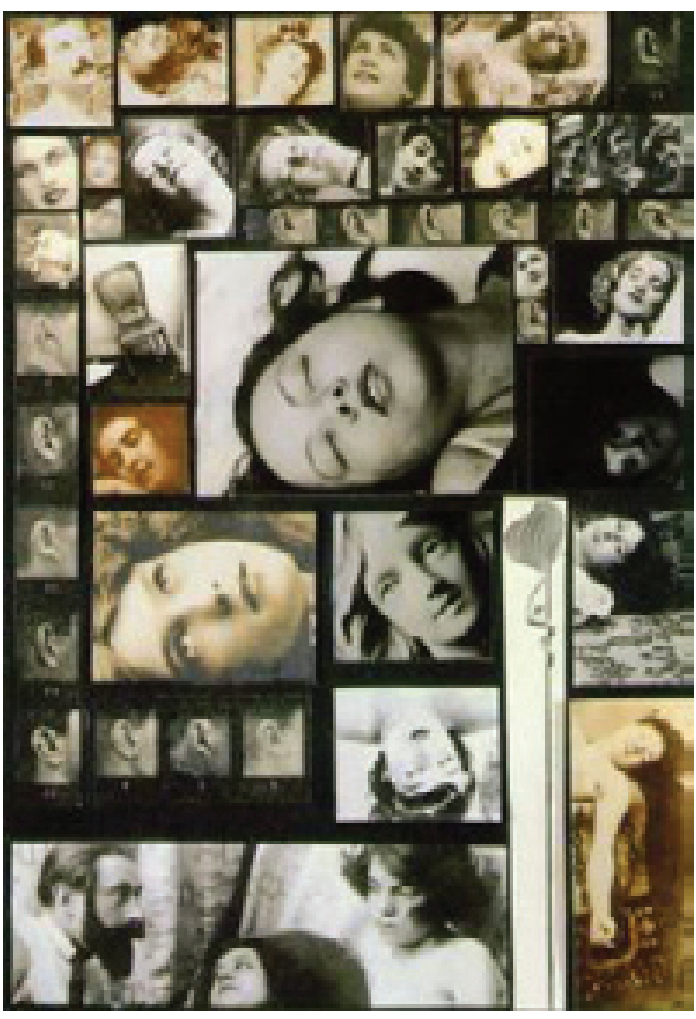

Figura 11 - Salvador Dali, 0 fenômeno do êxtase, 1933. Fonte: 〈http:www.dl-salvadordali. blogspot.com/>. Acesso em 20.fev.2010.

Entretanto, percebe-se que estas manifestações art nouveau indicam para além desta atitude de revolta e libertação da imposição da tradição. Na acepção de Jacques Lacan (1992), definimo-nos a partir de um fora, a partir de uma imagem que geralmente nos é próxima. A imagem significante seria de início local de toda alienação (LACAN, 1992), pois seria um sujeito que não sabe o que diz, seria formada por outro, outro responsável por sua subjetivação. As linhas do art nouveau, neste sentido, indicam esta tentativa de aproximação à natureza, uma tentativa de reaproximação da antiga unidade entre arte e técnica.

Em Paris, Capital do Século XIX, Walter Benjamin (BENJAMIN in KOTHE, 1991) afirma que a verdadeira significação do art nouveau estava mais de acordo com as concepções do próprio fazer artístico, representando uma última tentativa de superar a separação entre arte e técnica que ocorria então, uma tentativa designada por Sembach (2007) como a "utopia da reconciliação" . Dentro desta perspectiva é interessante destacar que, após a metade do século XIX, muitos seguidores de William Morris tomaram um caminho diverso do mestre e optaram pela defesa da reabilitação das artes aplicadas, mas associando-a com a indústria, em conformidade com os novos recursos oferecidos pela então emergente técnica moderna.

Reconciliar arte e técnica teria sido, conforme explicitado por Benjamin (BENJAMIN in KOTHE, 1991), o objetivo essencial do art nouveau e pode ser feita uma analogia com uma reconciliação entre homem e natureza. 0 artesanato, que de certa forma é uma atividade onde o homem reproduz os processos naturais (ARGAN, 1992), pode ser percebido como uma relação harmoniosa do homem com o meio. 
Os processos industriais solaparam esta relação, subtraindo a capacidade criativa do artesão e constituíam-se de um domínio sobre e uma modificação da natureza.

Deste modo, pode-se dizer que a cisão do que nos olha no que vemos (DIDI-HUBERMANN, 1998), a rachadura da imagem, aquilo que deixa ver seu fundo, tanto nas expressões de van de Velde como em algumas outras art nouveau, aponta para o grito último deste afastamento gradual da natureza, o reconhecimento da impossibilidade de unir arte e técnica.

E isto vai se refletir principalmente nas formas criadas, que a partir de então não confeririam mais a anterior possibilidade de reconhecimento do homem. Jean Baudrillard (1973) irá afirmar que a estética funcional - que, com van de Velde e o art nouveau teve sua deflagração inicial -, vai estar ligada ao fim de toda uma dimensão simbólica que unia o ser humano aos objetos e arquiteturas, "frustração de uma dimensão simbólica de reconhecimento"; ainda mais, "é na conivência profunda, na percepção visceral de nosso próprio corpo, que somos frustrados pela ordem moderna: nela não reencontramos mais grande coisa de nossos próprios órgãos nem da organização somática" (1973, 61).

Pode-se perceber em outros artistas e arquitetos contemporâneos, em graus diferenciados, parte destas expressões fantasmáticas que enunciamos aqui, bem como uma visão mais aterradora da natureza, um tom de ameaça iminente:

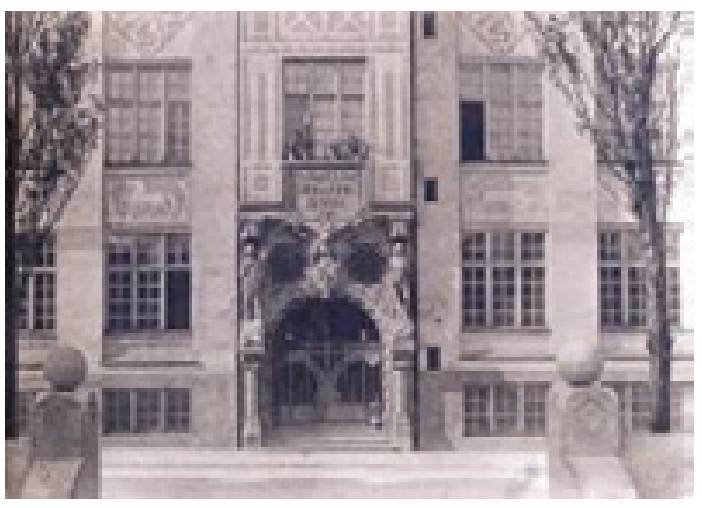

Figura 12 - Theodor Fischer, entrada da escola comunal da Haimhauserstrabe em Munique, 1898. Fonte: SEMBACH, Klaus-Jurgen. Arte Nova.Koln: Taschen, 2007

Figura 13 - Lucas Cranach, broche mostrando uma borboleta estrangulada por um polvo. Fonte: SEMBACH, Klaus-Jurgen. Arte Nova. Koln: Taschen, 2007

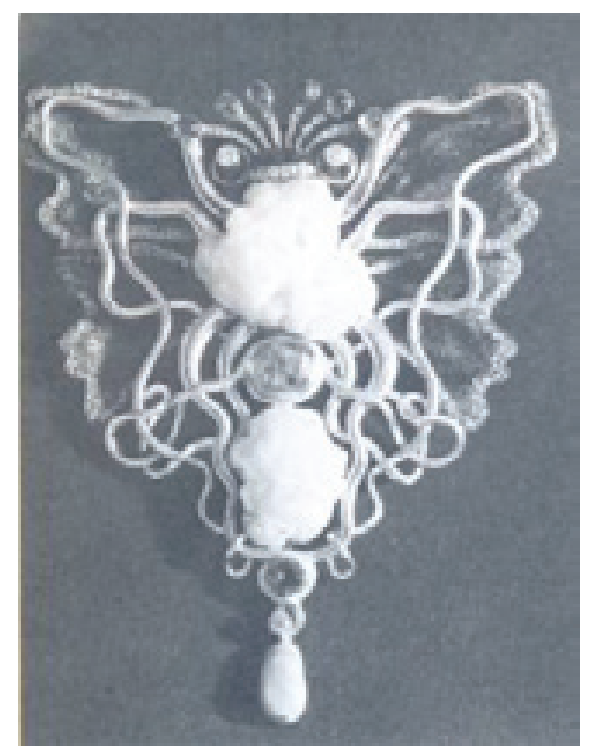


Nos países ocidentais, como França e Bélgica, este lado perverso e ameaçador do art nouveau também se fez notar, só que de forma mais explícita, com uma maior ênfase no figurativismo, o que iria de encontro com a tese de Worringer exposta anteriormente, como no candeeiro da imagem abaixo (figura 14) projetado por um designer de Bruxelas.

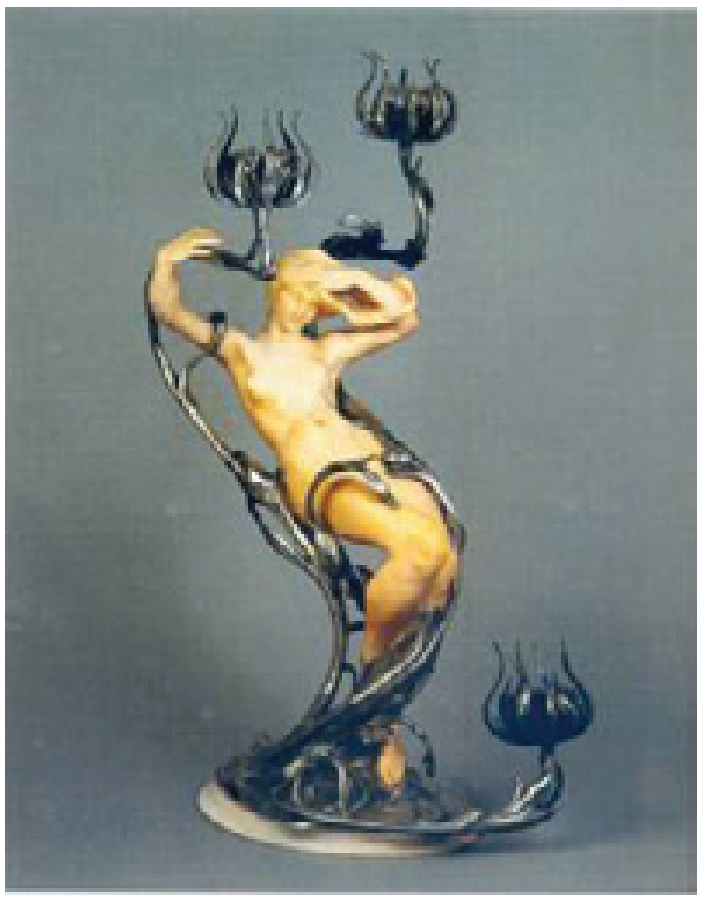

Figura 14 - Franz Hoosemans, candeeiro, 1900. Fonte: SEMBACH, Klaus-Jurgen. Arte Nova. Koln: Taschen, 2007

Nele se percebe uma jovem de longos cabelos envolta por uma espécie de planta com flores, talvez uma cena idílica de uma jovem em simbiose com uma planta florida. Em um olhar mais atento, pode-se perceber certo tom de ameaça vivido pela jovem representada na escultura - cuja imagem faz provavelmente referência à tradição clássica - a qual aparenta estar sendo devorada por certo tipo de vegetal que se assemelha de certa forma a alguma estilização de plantas carnívoras.

\section{A emenda da questão}

0 conflito arte e técnica, que envolve a relação mais geral do homem com a natureza, iria apresentar um aparente desfecho na história da arquitetura e do design praticamente em princípios do século XX, quando da criação em 1907 da Deutscher Werkbund, uma associação cuja pretensão inicial era aliar artesanato, arte e indústria na melhoria da criação dos objetos, aceitando tacitamente o favorecimento da indústria na produção dos objetos. Situação teoricamente estimulante, porém praticamente gerava conflitos, como o que se seguiu entre Hermann Muthesius e Henry van de Velde, em que o primeiro defendia, nesta imbricação de arte, 
artesanato e indústria, a padronização dos objetos industriais, enquanto o segundo optava pela individuação, pelo senso artístico na criação, pela presença única do artista na criação. 0 debate é claramente percebido nas declarações de Muthesius e de van de Velde, em aparente contradição:

A arquitetura, e com ela toda a área de atividade da Werkbund, dirige-se para a padronização (Typisierung)...Só a padronização pode...uma vez mais, introduzir um gosto universalmente válido e seguro (MUTHESIUS apUd PEVSNER, 1996, p.179)

Enquanto houver artistas na Werkbund...eles protestarão contra qualquer sugestão de um cânone de padronização. o artista, de acordo com sua essência mais profunda, é um individualista ferrenho, um criador livre e espontâneo. Ele nunca se submeterá voluntariamente a uma disciplina que o obrigue a um tipo, a um cânone (VAN DE VELDE apud PEVSNER, 1996, p. 179)

A própria proposta da associação, ao unir arte, artesanato e indústria, implicava muitas considerações que não deixaram de gerar conflito como esta que se seguiu. 0 fechamento desta querela já se sabe, o grupo de Muthesius sai vencedor com suas idéias de estandardização, e a linguagem padronizada da máquina, após a guerra, será adotada como proposta chave do movimento moderno.

A última resposta - se assim o podemos afirmar - de van de Velde a esta questão será também sua última grande aparição no cenário vanguardista: o grande Teatro da Werkbund, obra concebida justamente para a Exposição da Werkbund de 1914 em Colônia (figura 15), seu último grande monstro, ainda em linhas que remontam a formas naturais.

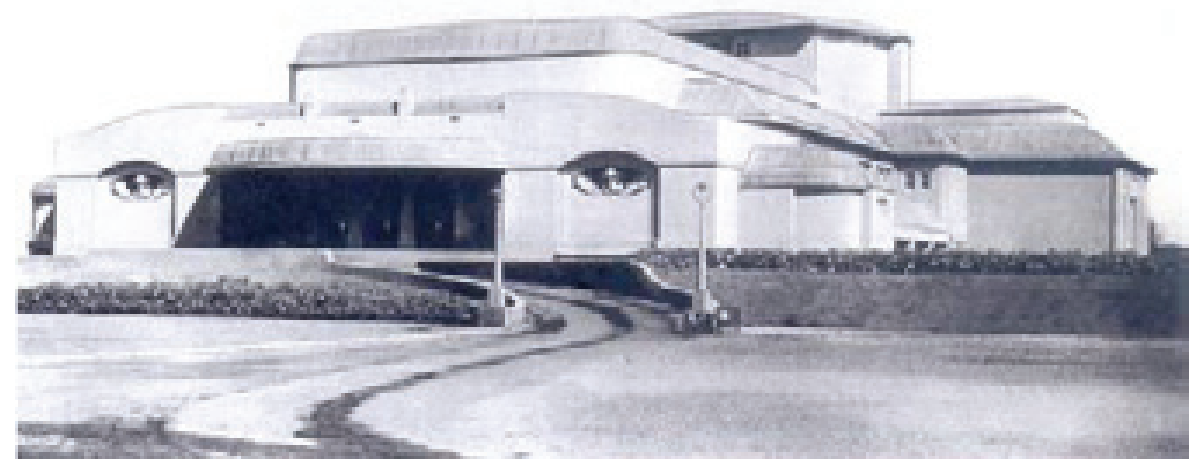

Figura 15 - Henry van de Velde, teatro construído para a exposição do Werkbund em Colônia, 1914. Fonte: SEMBACH, Klaus-Jurgen. Arte Nova. Koln: Taschen, 2007. 
Estabelecido o método de produção dos objetos modernos - a padronização industrial -, assim como sua linguagem formal - aquele do qual van de Velde foi um dos precursores e que rompia com a tradição formal do passado - , como continuidade desta novela moderna Baudrillard (1973) vai situar a quintessência do design do século XX, no qual aquela natureza rechaçada irá continuamente ressurgir através de indícios de uma conotação natural nas formas criadas.

0 autor afirma que, com o funcionalismo, a partir de determinado momento, "quando a estrutura congelada é invadida pelos elementos inestruturais, quando o detalhe formal invade 0 objeto, a função real passa a ser somente álibi e a forma passa somente a significar a idéia da função: torna-se alegórica" (1973, p.66). Finaliza ainda afirmando que "por toda a parte vê-se a idéia de natureza, sob múltiplas formas (elementos animais, vegetais, o corpo humano, o próprio espaço) imiscuir-se na articulação das formas" (1973, p.67). E cita como exemplo os carros que apresentam asas desenhadas, aludindo a signos que são dos pássaros e ao espaço propriamente dito.

Por fim, na arquitetura isto também irá ocorrer, quando alguns arquitetos abrem mão do estrito funcionalismo e utilizam formas mais expressivas, quando temos, em grande medida, um "retorno" do ornamento enquanto forma global da arquitetura, muitas destas arquiteturas apresentam em grande medida certa referência à natureza em um sentido conotado, alusivo, ou seja, certa semelhança formal a formas da natureza. Assim, a ópera de Sydney (figura 16) de Jorn Utzon, com bem afirmou Montaner (1993), é formada por enormes conchas sobre uma plataforma na água as conchas como elementos naturais, como se sabe, comumente possuem sua forma associada a um melhor desempenho acústico. Também no Museu Guggenheim de Nova York (figura 17), projetado por Frank Lloyd Wright, pode-se perceber certa alusão a rochas e cavernas - nada mais apropriado ao museu moderno, fechado sobre si mesmo, conotando características de elementos da natureza.

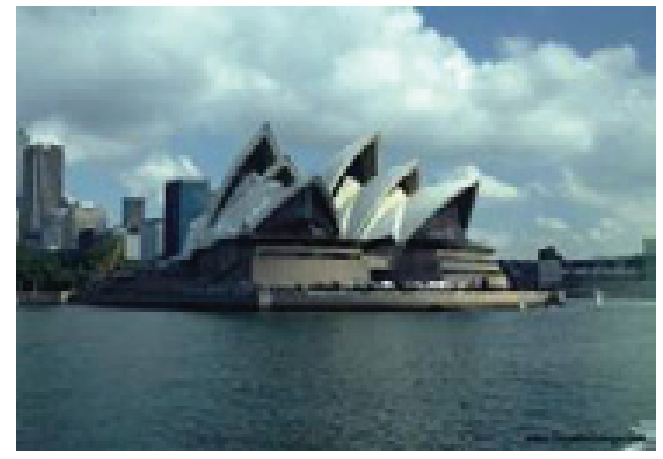

Figura 16 - Ópera de Sydney, Jorn Utzon. Disponivel em: 〈http: //www.greatbuildings.com〉. Acesso em 20 fev.2010.

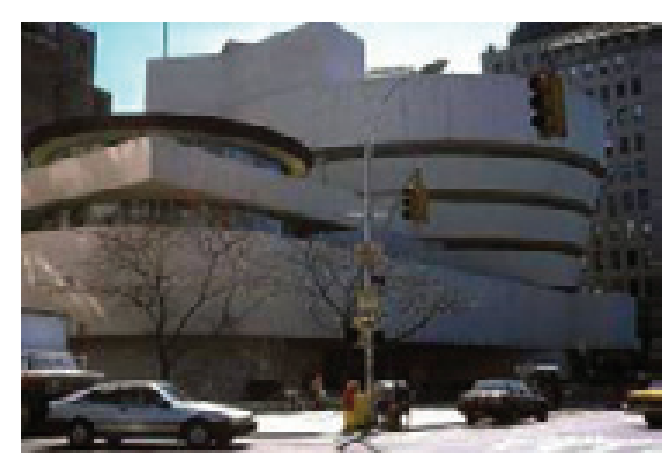

Figura 17 - Museu Guggenheim de Nova York, Frank LI. Wright. Disponível em: 〈http: //www. greatbuildings.com>. Acesso em 20. fev. 2010. 


\section{Referências Bibliográficas}

> ARGAN, Giulio Carlo. Arte Moderna. Do Iluminismo aos movimentos contemporâneos. SP: Cia das Letras, 1992.

> BENJAMIN, Walter. Paris, capital do século XIX. In: KOTHE, Flávio Rene (org.). Walter Benjamin: sociologia. São Paulo: Ática, 1991. A obra de arte na era de sua reprodutibilidade técnica. In:

Obras escolhidas. Magia e técnica, arte e política. 7. ed. SP: Brasiliense, 1994.

> BARTHES, Roland. 0 óbvio e o obtuso. SP: Martins Fontes, 1984.

> BAUDRILLARD, Jean. 0 Sistema dos Objetos. SP: Ed. Perspectiva, 1973.

> DALI, Salvador. Por qué se ataca a la Gioconda?. Madrid: Siruela, 2003.

> DIDI-HUBERMANN, Georges.0 que vemos, o que nos olha. São Paulo: Ed. 34, 1998.

> FER, Briony; BATCHELOR, David; WOOD, Paul. Realismo, racionalismo, surrealismo: arte no entre-guerras. SP: Cosac \&t Naify, 1998.

> FRAMPTON, Kenneth. História crítica da arquitetura moderna. São Paulo: Martins Fontes, 2003.

> GIEDION, Sigfried. Espaço, tempo e arquitetura: o desenvolvimento de uma nova tradição. São Paulo: Martins Fontes, 2004.

> KRAUSS, Rosalind. Caminhos da escultura moderna. SP: Martins Fontes, 1998.

> LACAN, Jacques. Subversão do sujeito e dialética do desejo no inconsciente freudiano. In: Escritos. 3.ed. São Paulo: Editora Perspectiva, 1992.

> MERLEAU-PONTY, Maurice. 0 olho e o espírito: seguido de A linguagem indireta e as vozes do silêncio e A dúvida de Cézanne. SP: Cosac đ̊ Naify, 2004.

> MONTANER. Josep Maria. Después del movimiento moderno. Barcelona: Editorial Gustavo Gili, 1993.

> PAIM, Gilberto. A beleza sob suspeita. RJ: Jorge Zahar, 2000.

> PEVSNER, Nikolaus. Origens da Arquitetura Moderna e do Design. SP: Martins Fontes, 1996.

> RUSKIN, John. The Seven Lamps of Architecture. New York: Dover Publications, 1989.

> RYKWERT, Joseph. Inheritance or tradition? In: Architectural Design. Londres: John Wiley, vol.49, $\mathrm{n}^{\circ}$ 5-6, 2-6, 1979.

> SEMBACH, Klaus-Jurgen. Arte Nova. A utopia da reconciliação. Koln: Taschen, 2007.

> VAN DE VELDE, Henry. Hacia un nuevo estilo. Buenos Aires: Editorial Nueva Vision, 1959.

> WORRINGER, Wilhelm. Abstraccion y Naturaleza. México: Fondo de Cultura Económica, 1953. 
Henry van de Velde, o art nouveau e a utopia da reconciliação

\section{Filmografia}

> JARDIM, João, CARVALHO, Walter. Janela da Alma. Produção de Flávio R. Tambellini . Direção de João Jardim e Walter Carvalho. Brasil, 2002. 73 min.

Alice de Oliveira Viana, professora Assistente do curso de Arquitetura e Urbanismo/UDESC-CERES (Centro de Educação Superior da Região Sul)

alice_viana@yahoo.com.br 